\title{
Recombinant Interleukin 2 and Gamma-Interferon Act Synergistically on Distinct Steps of In Vitro Terminal Human B Cell Maturation
}

Lê thi Bich-Thuy and Anthony S. Fauci

Laboratory of Immunoregulation, National Institute of Allergy and Infectious Diseases, National Institutes of Health, Bethesda, Maryland 20892; and the Institut National de la Santé et de la Recherche Medicale, France

\begin{abstract}
The effects of recombinant interleukin 2 (IL-2) on the in vitro differentiation of human tonsillar $B$ cells which were not preincubated with Staphylococcus aureus Cowan I or with anti-human IgM were investigated. IL-2 was shown to induce the generation of Ig-containing cells in a dose-dependent fashion from 2.5 to 2,500 U IL-2/ml. Conversely, the quantities of Ig secreted in the culture supernatant were found in the majority of experiments to peak at $25 \mathrm{U} / \mathrm{ml}$. The possible presence, in cultures stimulated with IL-2, of cells that were capable of synthesizing Ig but that did not secrete the Ig they have produced was investigated. Among a number of factors tested, we found that $\boldsymbol{\gamma}$-interferon, which did not trigger in vitro $B$ cell differentiation when used alone, can induce an increased secretion of Ig without noticeable change in the number of Ig-containing cells in cultures stimulated with IL-2. The possibility that $\boldsymbol{\gamma}$-interferon and IL-2 act on subsequent steps of in vitro $B$ cell differentiation is discussed.
\end{abstract}

\section{Introduction}

Interleukin 2 (IL-2) ${ }^{1}$ and $\gamma$-interferon ( $\gamma$-IFN) are among the most well-characterized lymphokines, both biochemically and with regard to their effects on various components of the immune response. However, their precise roles in the modulation of B cell differentiation still remain unclear. Using highly purified IL-2 produced by $T$ cells or $T$ cell clones stimulated either with antigen or mitogen, a number of independent studies have led to the conclusion that IL-2 can trigger murine B cell proliferation and/or differentiation, but this was due to the fact that either the IL-2 preparations contained some T cell helper factors for $B$ cells or IL-2 was actually acting on residual T cells contaminating $B$ cell preparations (1-3). Those residual $T$ cells were reported to be induced by IL-2 and antigen into either helper cells or helper factor-producing cells. Murine $\gamma$-IFN has been reported to induce antigen-stimulated $B$ cell differentiation in the presence of $T$ cell and/or macrophage supernatants (4-6), or to be a direct B cell-maturing lymphokine (7).

Dr. Lê thi Bich-Thuy's present address is Laboratory of Biochemistry, National Cancer Institute, Building 37, Room 4C19, Bethesda, MD 20892.

Address all correspondence to Dr. Fauci, National Institutes of Health, Building 10, Room 11B-13, Bethesda, MD 20892.

Received for publication 10 June 1985 and in revised form $10 \mathrm{De}$ cember 1985

1. Abbreviations used in this paper: AET-SRBC, S-2-aminoethylisothiouronium-bromide-treated sheep red blood cells; BCDF, B cell differentiation factor; IFN, interferon; Ig CC, Ig-containing cells; IL, interleukin; LPS, lipopolysaccharides; NK, natural killer, PFC, plaque-forming cells; PWM, pokeweed mitogen; SAC, Staphylococcus aureus Cowan I.

The Journal of Clinical Investigation, Inc.

Volume 77, April 1986, 1173-1179
Recent technological progress has allowed for the preparation of recombinant IL-2 and $\gamma$-IFN, both now available in large quantities. This has led to the publication of a number of reports which have created a new consensus: in vitro mitogen-preactivated murine (8) or human (9-11) B cells express receptors for IL-2 on their surface which allow them to proliferate in response to IL-2. However, controversial data still are being reported with regard to the in vitro differentiation of mitogen-preactivated $B$ cells in response to IL-2. For example, IL-2 has been reported to be unable, when used alone, to induce differentiation of normal human B cells stimulated with Staphylococcus aureus Cowan I (SAC) (12-14), or of murine B cells preactivated in vitro with anti-IgM (15). These data are consistent with those published by Pure et al. (16) demonstrating that IL-2 alone cannot induce IgM secretion by $\mathrm{BCL}_{1}$ tumor cells. Those authors demonstrated further that IL-2 did not enhance B cell differentiation factor (BCDF) $\mu$-induced IgM secretion by these cells, nor did it affect IgG synthesis by normal murine B cells treated with lipopolysaccharides (LPS) either in the presence or in the absence of BCDF- $\gamma(16)$. However, these findings are in contrast to data from Muraguchi et al. (11) and from Ralph et al. (17) which show that IL-2 can in fact induce human B cells preactivated by SAC to differentiate into Ig-secreting cells, and to data from Zubler et al. (8) demonstrating that IL-2 can induce murine B cells which have interacted with anti-mouse Ig during their preparation to differentiate into Ig-secreting cells provided they were exposed simultaneously to LPS and anti-IgM. In these studies, it was not reported whether IL-2 could act on freshly isolated $B$ cells in the absence of an in vitro preactivation step delivered by the addition of mitogen.

In the present report, using human tonsillar B cell preparations containing no detectable $T$ cells, monocytes, or natural killer cells both before and at the end of the cultures and recombinant IL-2 at doses ranging from 0 to $2,500 \mathrm{U} / \mathrm{ml}$, we demonstrated that IL-2 alone, when used at appropriate concentrations, induced the in vitro differentiation of $B$ cells which were not preactivated with either SAC or anti-IgM. The magnitude of the generation of Ig-containing cells (Ig CC) was found to be proportional to the concentrations of IL-2 added to cultures. Conversely, the addition of high concentrations of IL-2 did not result in an increase in the quantity of Ig secreted when compared with that obtained in cultures receiving low concentrations of IL-2. This suggests that there were cells in cultures containing high concentrations of IL-2 cells that were capable of synthesizing Ig but were still unable to secrete them. Further investigation showed that these cells required the presence of $\gamma$-IFN in addition to IL-2 in order to further undergo their terminal differentiation into fully committed Ig-secreting cells.

\section{Methods}

Cell suspensions. Human tonsillar mononuclear cells were partially depleted of $T$ cells by elimination of cells which have formed rosettes with S-2-aminoethylisothiouronium-bromide-treated sheep red blood cells (AET-SRBC). The resulting nonrosetting lymphocytes were allowed to 
undergo a second cycle of rosetting with sheep erythrocytes. The suspensions of nonrosetting cells will be referred to as AET- cells. They were subsequently incubated with a cocktail of monoclonal antibodies comprised of OKM1, OKT3 (Ortho Pharmaceuticals, Raritan, NJ), Leu1, Leu7, Leu5, Leu11 (Becton Dickinson and Co., Oxnard, CA). After washings, cells that bound one or more of these antibodies were eliminated from the cell suspensions after they were allowed to form rosettes with ox erythrocytes coated with goat $\left(\mathrm{Fab}^{\prime}\right)_{2}$ fragment anti-mouse Ig (Boehringer Mannheim Biochemicals, Indianapolis, IN). Only B cell-enriched suspensions (referred to as B cells) containing no detectable cells (out of $10^{4}$ cells counted) stained by one of the above-mentioned antibodies subsequently revealed by fluoresceinated goat $\left(\mathrm{Fab}^{\prime}\right)_{2}$ fragment anti-mouse Ig antibody (Tago Inc., Burlingame, CA) have been used in the experiments reported in this study. Under those conditions, no cell stained either by OKT3, OKM1, or the cocktail (Leu5 plus Leu7 plus Leu11) antibodies could be found in B cell cultures at the end of the cultures. The phenotype of cells in cultures containing IL-2 at day 7 are: 65.2 $\stackrel{\times}{\div} 1.4 \%$ bearing surface $\mathrm{Ig}, 22.7 \stackrel{\times}{\div} 1.3 \%$ of cells with morphology of classical plasma cells (i.e., an abundant cytoplasm containing Ig and a peripheral nucleus), and $12.5 \stackrel{\times}{\div} 1.5 \%$ of cells with a large nucleus surrounded by a scanty cytoplasm containing IgM without detectable surface Ig. The presence of Tac + cells was determined using immunofluorescence staining with anti-Tac antibody (kindly provided by Dr. T. A. Waldmann and his co-workers, Metabolism Branch, National Cancer Institute) followed by staining with fluoresceinated anti-mouse Ig antiserum (Tago, Inc.).

At day 4, cells from cultures containing IL-2 were split into two fractions. One fraction was treated with glycin- $\mathrm{HCl}$ buffer $(\mathrm{pH} 2.8)$ for $30 \mathrm{~s}$ in order to remove IL-2 which might have remained bound on Tac antigens and masked the anti-Tac antibody binding sites. Both fractions were then intensively washed before staining with anti-Tac antibody.

The possible contamination by $T$ cells of these suspensions has also been determined functionally. B cells (i.e., cells obtained after elimination of non-B cells by immune rosetting) did not respond to pokeweed mitogen (PWM), whereas AET- cells could readily differentiate in the presence of PWM (Table I).

Culture conditions. Culture medium was RPMI 1640 (Grand Island Biological Co., Grand Island, NY) supplemented with $10 \%$ fetal calf serum and gentamicin. All cultures were performed in a final volume of $1 \mathrm{ml}$ containing $5 \times 10^{5}$ cells in plastic tubes (Falcon Plastics, Oxnard, CA). Recombinant IL-2 (Hoffman-La Roche Corp., Nutley, NJ) and/or recombinant $\gamma$-IFN (Genentech Corp., South San Francisco, CA) were added, where indicated, at the beginning of the cultures in final concentrations from 0 to $2,500 \mathrm{U} / \mathrm{ml}$ and from 0 to $25,000 \mathrm{U} / \mathrm{ml}$, respectively.

Table I. Functional Control for the Absence of T Cell Helper Effects in B Cell Suspensions

\begin{tabular}{|c|c|c|c|c|}
\hline \multirow[b]{2}{*}{$\begin{array}{l}\text { Experi- } \\
\text { ment }\end{array}$} & \multirow[b]{2}{*}{ Cells } & \multicolumn{2}{|l|}{ Ig } & \multirow{2}{*}{$\begin{array}{l}{\left[{ }^{3} \mathrm{H}\right] \text { Thymidine }} \\
\text { uptake with } \\
\text { PWM }(1: 200)\end{array}$} \\
\hline & & PWM (1:200) & $\begin{array}{l}\text { IL-2 } \\
(2,500 \mathrm{U} / \mathrm{ml})\end{array}$ & \\
\hline \multirow{3}{*}{1} & & $n g / m l$ & & $c p m$ \\
\hline & AET- & $6,175 \stackrel{\times}{\div} 1.2$ & ND & $3,240 \stackrel{\times}{\div} 1.1$ \\
\hline & B & $111 \stackrel{\times}{\stackrel{\times}{\div}} 1.1$ & $5,880 \stackrel{×}{\leftarrow} 1.2$ & $619 \stackrel{\times}{\div} 1.1$ \\
\hline \multirow[t]{2}{*}{2} & AET- & $12,351 \stackrel{\times}{\stackrel{×}{1}} 1.2$ & ND & $7,192 \stackrel{\times}{\div} 1.2$ \\
\hline & B & $311 \stackrel{\times}{\div} 1.1$ & $4,666 \stackrel{\times}{\div} 1.1$ & $219 \stackrel{\times}{\div} 1.1$ \\
\hline \multirow[t]{2}{*}{3} & AET- & $3,759 \stackrel{\times}{\leftarrow} 1.3$ & ND & $1,240 \stackrel{\times}{\div} 1.1$ \\
\hline & B & $129 \stackrel{\times}{\div} 1.1$ & $7,270 \stackrel{×}{\leftarrow} 1.2$ & $197 \stackrel{\times}{\div} 1.1$ \\
\hline
\end{tabular}

AET- and B cells were prepared and cultured as detailed in Methods. Ig secretion was measured at day 7 . Results are expressed as geometric mean $\stackrel{\times}{-}$ SEM of duplicate assays of triplicate cultures.
Recombinant IL-2 used in this study had a specific activity of $2.2 \times 10^{6}$ $\mathrm{U} / \mathrm{mg}$, contained $<0.5 \%$ nucleic acids, and was $98.6 \%$ pure by sodium dodecyl sulfate-polyacrylamide gel electrophoresis. The unit of IL-2 was determined by comparison with the reference IL-2 isolated from the Jurkat cell line recommended by the International Union of Immunological Societies and provided by the Biological Response Modifiers Program of the National Cancer Institute. Recombinant $\gamma$-IFN had a specific activity of $6.8 \times 10^{7} \mathrm{U} / \mathrm{mg}$. These reagents contained only negligible levels of bacterial endotoxin at the concentrations used in this study $(<10 \mathrm{pg})$.

Anti $\gamma$-IFN antibody (Genentech) was added $(250 \mathrm{U} / \mathrm{ml})$ to cultures containing either IL-2 alone or IL-2 and $\gamma$-IFN $(250 \mathrm{U} / \mathrm{ml})$.

$B$ cell proliferation and differentiation assays. At the indicated time, aliquots containing $2.5 \times 10^{4}$ cells were transferred into microculture plates. $\left[{ }^{3} \mathrm{H}\right]$ Thymidine (New England Nuclear, Boston, MA) was added $(0.4 \mu \mathrm{Ci} /$ well $)$ and cells were harvested $4 \mathrm{~h}$ later. Two levels of $\mathrm{B}$ cell differentiation were assayed. The differentiation of B cells into Ig-synthesizing cells was quantitated by enumeration of cells containing Ig in their cytoplasm using a direct immunofluorescence staining procedure detailed elsewhere (18). Ig secretion was measured with an enzyme-linked immunosorbent assay as previously described (19). Ig-secreting cells were detected using a protein-A plaque-forming cell (PFC) assay as already detailed elsewhere (18).

Assay for endogenous $\gamma$-IFN production. At days 2, 4, and 6, $200 \mu$ of culture supernatants were tested for the presence of endogenously produced $\gamma$-IFN using the standard assay of inhibition of vesicular stomatitis viral infection of WISH cells (Biofluids, Inc., Rockville, MD).

\section{Results}

$B$ cell differentiation into Ig-synthesizing cells. The role of IL-2 in the induction of human B cells which were not preactivated in vitro with SAC or anti-IgM to differentiate into Ig-synthesizing cells was examined. Seven experiments were performed where the number of $\mathrm{Ig} C \mathrm{C}$ was determined at day 3, 6, and 9 of culture in the presence of IL-2 (from 0 to 2,500 U/ml). A similar pattern of results was obtained in all experiments despite the fact that the intensity of the response varied from experiment to experiment, which was probably due to the different immune status of our donors. Results from a representative experiment are presented in Fig. 1. As shown, a small increase in the number of Ig CC was observed at day 3 and became markedly pronounced at days 6 and 9 . The response was dose-dependent, with a plateau at $250 \mathrm{U} / \mathrm{ml}$ of IL-2 at day 6.

Cell proliferation was measured for each of these seven experiments. As mentioned above, the magnitude of the response varied from experiment to experiment. However, in all experiments, a similar pattern of data was observed. Table II shows the geometric means and their standard error of triplicate cultures from seven experiments.

$B$ cell differentiation into Ig-secreting cells. To investigate whether IL-2 can trigger the final steps of B cell differentiation, i.e., the maturation of Ig-synthesizing cells into Ig-secreting cells, the amount of $\operatorname{IgM}, \operatorname{IgG}$, and IgA secreted into the culture supernatants was measured at days 3,6, and 9. Seven separate experiments were performed, and comparable patterns were seen. A representative experiment is illustrated in Fig. 2 . The addition of IL-2 to human tonsillar B cells resulted in an increase of IgM and $\mathrm{IgG}$, although IgM was found to be predominantly produced (Fig. 2). The increase in IgA production in the presence of IL2 was found to be inconsistent. The enhancement of the Ig production was detectable at day 6 for IgM and at day 9 for IgG. No difference in IgG secretions was found between cultures containing high vs. low concentrations of IL-2. IgM production at day 9 reached a plateau at $25 \mathrm{U} / \mathrm{ml}$. Cultures receiving $2.5 \mathrm{U} /$ 


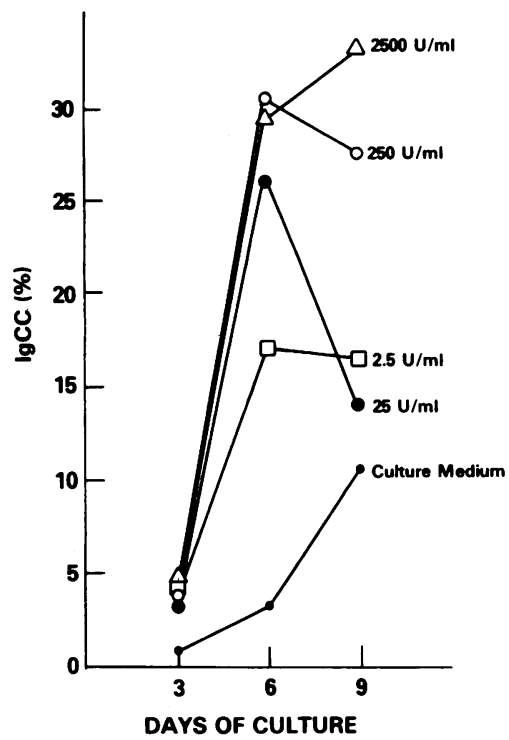

Figure 1. Kinetics of the generation of Ig-synthesizing cells induced by increasing concentrations of recombinant IL-2. Human tonsillar B cell suspensions were cultured with increasing concentrations of IL-2 (0$2500 \mathrm{U} / \mathrm{ml}$ ). Smears were prepared by cytocentrifugation at day 3,6 , and 9. Intracytoplasmic Ig were stained with a fluoresceinated goat anti-human Ig. Ig CC were enumerated under a microscope. Results are expressed as frequency of fluorescent cells. A similar pattern of results has been observed in six other experiments.

$\mathrm{ml}$ of IL-2 had less IgM than cultures containing from 25 to $2,500 \mathrm{U} / \mathrm{ml}$. However, this difference was small, ranging from 15 to $25 \%$ (Fig. 2). In two experiments, IL-2 at $0.25 \mathrm{U} / \mathrm{ml}$ failed to induce the generation of Ig CC or Ig production (data not shown), suggesting that this concentration of IL-2 is not sufficient to trigger $B$ cell differentiation.

Since the quantity of Ig secreted in culture was comparable in the presence of $25 \mathrm{U} / \mathrm{ml}$ of IL-2 as compared with $2,500 \mathrm{U} /$ $\mathrm{ml}$ of IL-2 (Fig. 2) and since there were markedly fewer Ig CC in cultures containing low vs. high concentrations of IL-2 (Fig. 1), it is likely that a proportion of the Ig CC in cultures containing high concentrations of IL-2 did not actually secrete their Ig. This led to the consideration of a possible requirement of another signal in addition to IL-2 for those Ig CC to further differentiate

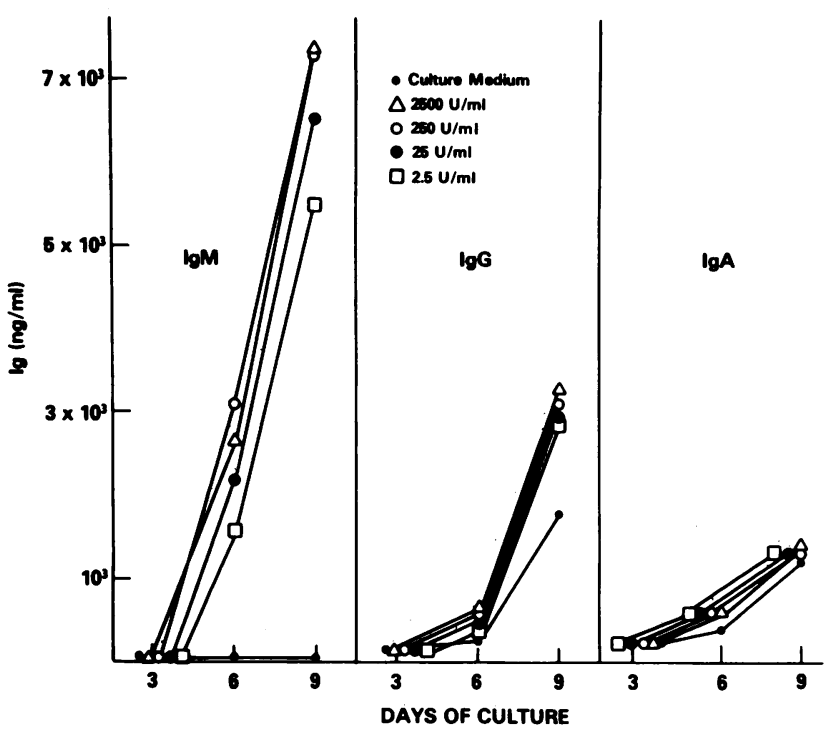

Figure 2. Kinetics of IgM, IgG, and IgA secretion induced by increasing concentrations of IL-2. Human tonsillar B cells were cultured with increasing concentrations of IL-2 $(0-2500 \mathrm{U} / \mathrm{ml})$. IgM, IgG, and IgA in cultures were assayed at day 3,6 , and 9 by enzyme-linked immunosorbent assay. Results are expressed as nanograms per milliliter.

into Ig-secreting cells. This hypothesis was further investigated using $\gamma$-IFN as a cohelper factor.

Synergy between IL-2 and $\gamma-I F N$ in the induction of $B$ cell differentiation. To determine the potential synergistic relationship between IL-2 and $\gamma$-IFN in the induction of B cell differentiation, it was first necessary to determine the effects of $\gamma$-IFN alone on B cell differentiation in our system. We have found that no effects of $\gamma$-IFN could be demonstrated either on the generation of $\mathrm{Ig} \mathrm{CC}$ or on the secretion of Ig at any concentration tested from 0 to $25,000 \mathrm{U} / \mathrm{ml}$. The effect(s) of $\gamma$-IFN on IL-2induced B cell differentiation was investigated in experiments where either IL-2 alone, $\gamma$-IFN alone, or both were added to cultures of B cells (Table III). The addition of IL-2 alone resulted in an increase in the numbers of Ig CC and in the quantity of Ig secreted in the culture supernatants when compared with controls with no IL-2 added, thus confirming data reported above. The addition of $\gamma$-IFN alone to cultures did not lead to

Table II. Proliferation of In Vitro Nonactivated Human Tonsillar B Cells in Response to IL-2

\begin{tabular}{|c|c|c|c|c|c|c|c|}
\hline \multirow[b]{2}{*}{ IL-2 } & \multicolumn{3}{|c|}{$\left[{ }^{3} \mathrm{H}\right]$ Thymidine uptake } & \multirow[b]{2}{*}{ Activators } & \multicolumn{3}{|l|}{ Tac $^{+}$cells* } \\
\hline & Day 3 & Day 6 & Day 9 & & Day 0 & Day 4 & Day 7 \\
\hline & $c p m$ & cpm & cpm & & $\%$ & $\%$ & $\%$ \\
\hline 0 & $247 \stackrel{\times}{\div} 1.1$ & $752 \stackrel{\times}{\div} 1.3$ & $522 \stackrel{\times}{\div} 1.3$ & 0 & $1.9 \stackrel{\times}{\div} 1.3$ & $2.1 \stackrel{\times}{\div} 1.2$ & $1.3 \stackrel{\times}{\div} 1.5$ \\
\hline 25 & $1,154 \stackrel{\times}{\div} 1.3$ & $9,316 \stackrel{\times}{\div} 1.2$ & $3,535 \stackrel{\times}{\div} 1.2$ & IL-2‡ & NDI & $6.9 \stackrel{\times}{\div} 1.3$ & $4.5 \stackrel{\times}{\div} 1.5$ \\
\hline 250 & $2,908 \stackrel{\times}{\div} 1.2$ & $10,698 \stackrel{\times}{\div} 1.1$ & $7,135 \stackrel{\times}{\div} 1.2$ & IL-2§ & ND & $6.4 \stackrel{\times}{\div} 1.3$ & ND \\
\hline 2,500 & $3,540 \stackrel{\times}{\div} 1.3$ & $11,825 \stackrel{\times}{\div} 1.3$ & $7,135 \stackrel{\times}{\div} 1.2$ & $\operatorname{SAC}(1: 12,500)$ & ND & $41.3 \stackrel{\times}{\div} 1.2$ & $24.2 \stackrel{\times}{\div} 1.4$ \\
\hline
\end{tabular}

At the indicated time, aliquots containing $2.5 \times 10^{4}$ cells were transferred into microculture plates. $\left[{ }^{3} \mathrm{H}\right] \mathrm{Thymidine}(0.4 \mu \mathrm{Ci} /$ well $)$ was added and cells were harvested $4 \mathrm{~h}$ later. Results are expressed as geometric mean $\stackrel{\times}{\leftarrow}$ SEM of triplicate cultures from seven experiments. ${ }^{*}$ Tac $^{+}$cells were stained by immunofluorescence as detailed in Methods at the initiation and $4 \mathrm{~d}$ of culture. Results are expressed as geometric mean $\stackrel{\times}{\div}$ SEM of seven experiments. ‡Without treatment with glycin buffer. § Treated with glycin buffer before staining. T Not done. 
enhancement of Ig production or of the number of Ig CC. However, when added to cultures containing IL-2, $\gamma$-IFN induced a marked increase in the quantity of Ig secreted in culture supernatants without noticeable change in the numbers of Ig CC. Of note, the synergy between IL-2 and $\gamma$-IFN was not confined to a given Ig class, since it affects the production of $\mathrm{IgG}$, IgM, and IgA (Table III).

To determine whether Ig secretion in IL-2 stimulated cultures was due to endogenous production of $\gamma$-IFN, the presence of $\gamma$ IFN in IL-2-containing cultures was assayed. We found that IL2-stimulated cultures did not contain more $\gamma$-IFN than control culture receiving no IL-2, provided $B$ cell suspensions had been stringently depleted of non-B cells (i.e., depletion of AET rosetting cells and elimination by immune rosetting of cells recognized by a cocktail of monoclonal anti-T cell, anti-natural killer (NK) cell, and anti-monocyte antibodies). We next determined whether the enhanced secretion of Ig was due to exogenous $\gamma$-IFN added to cultures. For this purpose, anti- $\gamma$-IFN antibody was added at neutralizing concentrations simultaneously to cultures with IL-2 or IL-2 and $\gamma$-IFN. In these experiments, the presence of anti- $\gamma$-IFN antibody did not alter Ig synthesis and Ig secretion in IL-2-containing cultures. In cultures receiving IL-2, $\gamma$-IFN, and anti- $\gamma$-IFN antibody, Ig secretion was reduced to about the level observed in cultures containing IL-2 alone, whereas the number of Ig CC remained unchanged.

Characteristics of the synergy between IL-2 and $\gamma-I F N$. In four experiments, the kinetics of the synergy between IL-2 and $\gamma$-IFN were investigated. As shown in Table IV, the addition of $\gamma$-IFN either at day $0,1,2$, or 3 led to a similar degree of enhancement of Ig secretion in culture supernatants.
To determine whether the increase in the concentrations of Ig secreted may be due to an enhanced generation of Ig-secreting cells, we have counted the number of PFC in a series of seven experiments. Table $\mathrm{V}$ shows the mean of data from seven experiments. As can be seen, there were markedly higher numbers of PFC in cultures containing IL- 2 and $\gamma$-IFN than in cultures containing IL-2 alone.

\section{Discussion}

The present study demonstrates that in the presence of recombinant IL-2, differentiation of human B cells which were not intentionally preactivated in vitro with antigen or mitogen occurred. The amount of Ig secreted as well as the kinetics of Ig production were comparable with that which could be obtained in cultures of lymphocytes stimulated with T-independent polyclonal B cell activators (Lê thi Bich-Thuy, unpublished observations). The quantities of Ig secreted into the culture supernatants reached a plateau at $25 \mathrm{U} / \mathrm{ml}$ of added IL-2, while the differentiation of B cells into Ig-synthesizing cells was dependent upon the doses of IL-2 added to the cultures. Of note, the level of differentiation of $B$ cells which have received in vivo the required signals to complete their differentiation in vitro in the absence of IL- 2 was shown on Figs. 1 and 2 in culture with no IL-2 added. It was far lower than that observed in the presence of exogenous IL-2.

The experiments in the present study were performed using B cell suspensions containing no detectable $T$ cells, monocytes, or NK cells both at the initiation and at the end of cultures. Furthermore, these cells did not respond to PWM (Table I), nor did they produce $\gamma$-IFN above the background detected in con-

Table III. Synergy Between IL-2 and $\gamma$-IFN in the Differentiation of Human B Cells

\begin{tabular}{|c|c|c|c|c|c|c|}
\hline \multirow{2}{*}{$\begin{array}{l}\text { Experi- } \\
\text { ment }\end{array}$} & \multirow{2}{*}{$\begin{array}{l}\text { Lymphokines } \\
\text { added }\end{array}$} & \multicolumn{3}{|l|}{ Ig } & \multirow[b]{2}{*}{$\mathrm{IgCC}$} & \multirow[b]{2}{*}[{}^{3}\mathrm{H}]{ Thymidine } \\
\hline & & IgM & IgG & IgA & & \\
\hline & & $n g / m l$ & $n g / m l$ & $n g / m l$ & & $c p m$ \\
\hline \multirow[t]{4}{*}{1} & None & $85 \stackrel{\times}{\div} 1.1$ & $268 \stackrel{\times}{\div} 1.1$ & $436 \stackrel{\times}{\div} 1.1$ & 3.3 & $175 \stackrel{\times}{\div} 1.1$ \\
\hline & IL-2 & $2,237 \stackrel{\times}{\stackrel{×}{\div}} 1.1$ & $457 \stackrel{\times}{\div} 1.1$ & $587 \stackrel{\times}{\div} 1.1$ & 26.4 & $3,912 \stackrel{\times}{\div} 1.1$ \\
\hline & $\gamma$-IFN & $161 \stackrel{\times}{\div} 1.2$ & $189 \stackrel{\times}{\div} 1.1$ & $326 \stackrel{\times}{\div} 1.1$ & 1.7 & $328 \stackrel{\times}{\div} 1.2$ \\
\hline & IL-2 plus $\gamma$-IFN & $4,541 \stackrel{\times}{\div} 1.1$ & $731 \stackrel{\times}{\stackrel{x}{1}} 1.1$ & $689 \stackrel{\times}{\stackrel{x}{\div} 1.1}$ & 25.5 & $3,981 \stackrel{\times}{\div} 1.1$ \\
\hline \multirow[t]{4}{*}{2} & None & $61 \stackrel{\times}{\div} 1.1$ & $320 \stackrel{\times}{\div} 1.1$ & $383 \stackrel{\times}{\div} 1.1$ & 4.7 & $328 \stackrel{\times}{\div} 1.1$ \\
\hline & IL-2 & $8,056 \stackrel{\times}{\div} 1.1$ & $1,580 \stackrel{\times}{\div} 1.1$ & $427 \stackrel{\times}{\div} 1.1$ & 32.4 & $7,171 \stackrel{\times}{\div} 1.1$ \\
\hline & $\gamma$-IFN & $197 \stackrel{\times}{\div} 1.1$ & $340 \stackrel{\times}{\div} 1.1$ & $52 \stackrel{\times}{\div} 1.4$ & 5.1 & $357 \stackrel{\times}{\div} 1.1$ \\
\hline & IL-2 plus $\gamma$-IFN & $17,249 \stackrel{\times}{\div} 1.1$ & $2,060 \stackrel{\times}{\div} 1.1$ & $744 \stackrel{\times}{\div} 1.1$ & 28.1 & $7,785 \stackrel{\times}{\div} 1.1$ \\
\hline \multirow[t]{4}{*}{3} & None & $21 \stackrel{\times}{\stackrel{x}{\circ}} 1.3$ & $160 \stackrel{\times}{\div} 1.1$ & $15 \stackrel{\times}{\div} 1.1$ & 1.1 & $113 \stackrel{\times}{\div} 1.2$ \\
\hline & IL-2 & $2,087 \stackrel{\times}{\stackrel{\times}{\div}} 1.1$ & $560 \stackrel{\times}{\div} 1.1$ & $57 \stackrel{x}{\div} 1.1$ & 21.8 & $4,571 \stackrel{\times}{\div} 1.3$ \\
\hline & $\gamma$-IFN & $25 \stackrel{\times}{\stackrel{×}{\circ} 1.1}$ & $240 \stackrel{\times}{\stackrel{x}{\leftrightarrows}} 1.1$ & $61 \stackrel{x}{\stackrel{ }{\circ}} 1.1$ & 1.4 & $779 \stackrel{\times}{\div} 1.3$ \\
\hline & IL-2 plus $\gamma$-IFN & $6,906 \stackrel{\times}{\div} 1.1$ & $980 \stackrel{\times}{\div} 1.1$ & $190 \stackrel{\times}{\div} 1.1$ & 22.1 & $4,543 \stackrel{\times}{\div} 1.1$ \\
\hline
\end{tabular}

B cells were added with either culture medium, IL-2 $(250 \mathrm{U} / \mathrm{ml}), \gamma$-IFN $(250 \mathrm{U} / \mathrm{ml})$, or IL-2 $(250 \mathrm{U} / \mathrm{ml})$ and $\gamma$-IFN $(250 \mathrm{U} / \mathrm{ml})$ simultaneously. IgCC and secreted IgM, IgG, or IgA were assayed at day 5. Concentrations of Ig are expressed as geometric mean $\underset{-}{\times}$ SEM of duplicate assays of triplicate cultures. Proliferative assays were performed with $2.5 \times 10^{4}$ cells incubated with $0.4 \mu \mathrm{Ci}\left[{ }^{3} \mathrm{H}\right]$ thymidine for $4 \mathrm{~h}$. Results are expressed as geometric mean $\stackrel{\times}{\leftarrow}$ SEM of triplicate cultures. 
Table IV. Kinetics of the Synergy Between IL-2 and $\gamma-I F N$ in the Differentiation of Human B Cells

\begin{tabular}{|c|c|c|c|c|c|c|c|c|}
\hline \multirow{2}{*}{$\begin{array}{l}\text { Experi- } \\
\text { ment }\end{array}$} & \multirow{2}{*}{$\begin{array}{l}\text { Lymphokines } \\
\text { added* }\end{array}$} & \multicolumn{7}{|c|}{ Addition of $\gamma$-IFN at: } \\
\hline & & Day 0 & Day 1 & Day 2 & Day 3 & Day 4 & Day 5 & Day 6 \\
\hline \multirow[t]{4}{*}{1} & None & $100 \stackrel{\times}{\div} 1.1$ & & & & & & \\
\hline & IL-2 & $5,880 \stackrel{\times}{\div} 1.2$ & & & & & & \\
\hline & $\gamma$-IFN & $114 \stackrel{\times}{\div} 1.4$ & $175 \stackrel{\times}{\div} 1.1$ & $101 \stackrel{\times}{\div} 1.1$ & $99 \stackrel{\times}{\div} 1.2$ & $59 \stackrel{\times}{\div} 1.1$ & $60 \stackrel{\times}{\div} 1.1$ & $81 \stackrel{\times}{\div} 1.1$ \\
\hline & IL-2 plus $\gamma$-IFN & $14,258 \stackrel{\times}{\div} 1.1$ & $16,425 \stackrel{\times}{\div} 1.2$ & $12,750 \stackrel{\times}{\div} 1.1$ & $12,750 \stackrel{\times}{\div} 1.1$ & $8,150 \stackrel{\times}{\div} 1.1$ & $9,350 \stackrel{\times}{\div} 1.1$ & $6,650 \stackrel{\times}{\div} 1.1$ \\
\hline \multirow[t]{4}{*}{2} & None & $112 \stackrel{\times}{\div} 1.1$ & & & & & & \\
\hline & IL-2 & $4,665 \stackrel{\times}{\div} 1.1$ & & & & & & \\
\hline & $\gamma$-IFN & $301 \stackrel{\times}{\div} 1.1$ & $450 \stackrel{\times}{\div} 1.1$ & $102 \stackrel{\times}{\div} 1.2$ & 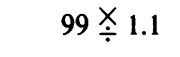 & $251 \stackrel{\times}{\stackrel{x}{\div}} 1.1$ & $162 \stackrel{\times}{\div} 1.1$ & $104 \stackrel{\times}{\div} 1.1$ \\
\hline & IL-2 plus $\gamma$-IFN & $12,720 \stackrel{\times}{\div} 1.1$ & $12,900 \stackrel{\times}{\div} 1.1$ & $9,700 \stackrel{\times}{\div} 1.2$ & $11,150 \stackrel{\times}{\div} 1.1$ & $12,250 \stackrel{\times}{\div} 1.3$ & $8,750 \stackrel{\times}{\div} 1.1$ & $7,056 \stackrel{\times}{\div} 1.1$ \\
\hline \multirow[t]{4}{*}{3} & None & $107 \stackrel{\times}{\div} 1.1$ & & & & & & \\
\hline & IL-2 & $7,270 \stackrel{\times}{\div} 1.1$ & & & & & & \\
\hline & $\gamma$-IFN & $151 \stackrel{\times}{\div} 1.2$ & $111 \stackrel{\times}{\div} 1.1$ & $117 \stackrel{\times}{\div} 1.7$ & $101 \stackrel{\times}{\div} 1.1$ & $97 \stackrel{\times}{\div} 1.1$ & $182 \stackrel{\times}{\div} 1.1$ & $150 \stackrel{\times}{\div} 1.1$ \\
\hline & IL-2 plus $\gamma$-IFN & $15,160 \stackrel{\times}{\div} 1.1$ & $15,601 \stackrel{\times}{\div} 1.1$ & $16,601 \stackrel{\times}{\div} 1.1$ & $13,310 \stackrel{\times}{\leftarrow} 1.1$ & $7,840 \stackrel{\times}{\leftarrow} 1.1$ & 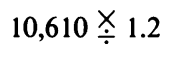 & $10,400 \stackrel{\times}{\stackrel{×}{\leftrightarrows}} 1.2$ \\
\hline \multirow[t]{4}{*}{4} & None & $760 \stackrel{\times}{\div} 1.2$ & & & & & & \\
\hline & IL-2 & $3,760 \stackrel{\times}{\div} 1.1$ & & & & & & \\
\hline & $\gamma$-IFN & $520 \stackrel{\times}{\div} 1.1$ & $650 \stackrel{\times}{\div} 1.1$ & $810 \stackrel{\times}{\div} 1.1$ & $440 \stackrel{\times}{\div} 1.1$ & ND $\ddagger$ & $1,450 \stackrel{×}{\stackrel{×}{\circ} 1.3}$ & ND \\
\hline & IL-2 plus $\gamma$-IFN & $6,330 \stackrel{\times}{\div} 1.1$ & $6,330 \stackrel{\times}{\div} 1.1$ & $6,520 \stackrel{\times}{\div} 1.1$ & $5,950 \stackrel{\times}{\div} 1.1$ & $6,550 \stackrel{\times}{\stackrel{×}{1} 1.1}$ & $4,080 \stackrel{\times}{\stackrel{×}{\div}} 1.1$ & $3,090 \stackrel{\times}{\div} 1.1$ \\
\hline
\end{tabular}

* B cells prepared as detailed in Methods were cultured without lymphokines or with IL-2 $(250 \mathrm{U} / \mathrm{ml})$. $\gamma$-IFN was added at the indicated time. Ig secretion was assayed at day 7 . Results are expressed in nanograms per milliliter as the geometric mean $\stackrel{x}{\leftarrow}$ SEM of duplicate assays of triplicate cultures. $\ddagger$ Not done.

trol cultures without IL-2. However, we cannot firmly rule out the possibility that one or more of these non-B cells may still be present at undetectable levels and may provide help for B cells to respond to IL-2. Of note, tonsillar B cells were used in this study since no detectable NK activity could be detected in tonsils (20). Furthermore, the lack of cells stained by OKM1 antibody or by the cocktail (Leu5 plus Leu7 plus Leu11) both at the initiation and at the termination of the cultures argues against the presence of NK cells (20).
In our hands, no requirement for an in vitro preactivation signal delivered by preincubation with either mitogen or antigen was needed for B cells to differentiate in response to IL-2. Since the IL-2 used in this study was produced by Escherichia coli carrying human genes coding for IL-2, the possibility exists that contaminating bacterial LPS replaced a mitogen or antigen preactivation signal. However, in control experiments, we have repeatedly observed that LPS had no detectable effects on human B cell differentiation when used at concentrations of $0.01-1 \mu \mathrm{g} /$

Table V. $\gamma$-IFN Synergized with IL-2 by Enhancing the Generation of PFC in Cultures Stimulated with IL-2

\begin{tabular}{|c|c|c|c|c|c|c|c|}
\hline \multirow{2}{*}{$\begin{array}{l}\text { Lymphokines } \\
\text { added* }\end{array}$} & \multirow[b]{2}{*}{ Viable cells } & \multirow[b]{2}{*}{ Ig CC } & \multirow[b]{2}{*}{ PFC } & \multicolumn{4}{|l|}{ Ig } \\
\hline & & & & IgM & $\lg G$ & $\lg A$ & $\operatorname{Ig} A+\lg G+\lg M$ \\
\hline & $10^{6}$ cells/culture & $\%$ & $110^{6}$ viable cells & $n g / m l$ & $n g / m l$ & $n g / m l$ & $n g / m l$ \\
\hline None & $0.77 \stackrel{\times}{\div} 1.3$ & $2.7 \stackrel{\times}{\div} 1.3$ & $1,102 \stackrel{\times}{\div} 1.2$ & $187 \stackrel{\times}{\div} 1.3$ & $380 \stackrel{\times}{\div} 1.2$ & $240 \stackrel{\times}{\stackrel{\times}{\leftrightarrows}} 1.3$ & 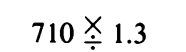 \\
\hline IL-2 & $1.22 \stackrel{\times}{\div} 1.2$ & $18.5 \stackrel{x}{\div} 1.4$ & $3,587 \stackrel{\times}{\div} 1.3$ & $2,240 \stackrel{\times}{\div} 1.3$ & $576 \stackrel{\times}{\div} 1.5$ & $265 \stackrel{\times}{\div} 1.5$ & $2,581 \stackrel{\times}{\stackrel{\times}{\div}} 1.3$ \\
\hline$\gamma$-IFN & $0.83 \stackrel{\times}{\div} 1.4$ & $2.9 \stackrel{\times}{\div} 1.4$ & $1,540 \stackrel{×}{\div} 1.4$ & $490 \stackrel{\times}{\div} 1.4$ & $340 \stackrel{\times}{\div} 1.4$ & $159 \stackrel{\times}{\div} 1.4$ & $952 \stackrel{\times}{\div} 1.3$ \\
\hline IL-2 plus $\gamma$-IFN & $1.11 \stackrel{\times}{\div} 1.3$ & $19.7 \stackrel{\times}{\div} 1.4$ & $9,277 \stackrel{\times}{\div} 1.3$ & $4,590 \stackrel{\times}{\div} 1.3$ & $1,085 \stackrel{\times}{\div} 1.3$ & $942 \stackrel{\times}{\div} 1.4$ & 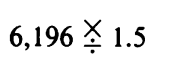 \\
\hline
\end{tabular}

* B cells were prepared and cultured as detailed in Methods. IL-2 and $\gamma$-IFN were added at $250 \mathrm{U} / \mathrm{ml}$ at the initiation of cultures. Assays were

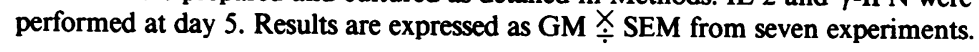


ml, which are far higher concentrations than that of the contamination of IL-2 preparation used in this study, nor did they synergize with IL-2 in inducing human B cell differentiation (data not shown). Furthermore, care was taken not to activate B cells in the fractionation procedure in that they were obtained by a negative selection protocol which consisted of incubation and centrifugation on Hypaque-Ficoll gradients without obvious perturbation of surface Ig or surface antigen on B cell membranes. It is of note that most of the studies leading to the conclusions that B cells must be rechallenged in vitro with antigen or preactivated with mitogen in order to respond to IL-2 were performed with suboptimal doses of IL-2 (1-3). It is possible that IL-2 at low concentrations cannot act on cells bearing either low numbers of IL-2 receptors or low affinity receptors and that mitogen or antigen were required in order either to expand the density of IL-2 receptors or to induce receptors with sufficient avidity for low concentrations of this lymphokine. The first hypothesis is given added credence by descriptions of the marked heterogeneity of IL-2 receptor density on the surface of normal $T$ cells (21). In this regard, at limiting IL-2 concentrations, only $\mathrm{T}$ cells bearing high density receptors for IL- 2 are triggered by IL-2 (21). The second possibility is supported by the existence of low affinity receptors for IL-2, which have been described on leukemic cell membranes (21) and on various human cell types (22). Of note, unknown activators which might be present in culture medium or signals which might have been received during the cell fractionation procedure did not preactivate B cells into Tac antigen-bearing cells, since there was no increase in the number of $\mathrm{Tac}^{+}$cells after 4-d incubation of cells in culture medium. Similarly, possible "in vivo-preactivation" did not lead to the expression of detectable Tac antigens on the cell surface, because $<2 \% \mathrm{Tac}^{+}$cells were found at the initiation of cultures. Furthermore, removal of these $\mathrm{Tac}^{+}$cells did not impair B cell responsiveness to IL-2. The possibility that IL-2 may act on in vivo preactivated $B$ cells remains an open question. With this being the case, the fact that B cells can respond to IL-2 by virtue of their in vivo status may be important in clinical trials using IL-2 as an immunopharmacologic agent.

When B cells were cultured with IL-2 for $4 \mathrm{~d}$, only a maximum of $7 \%$ of them expressed Tac antigens. The proportion of $\mathrm{Tac}^{+}$cells decreased after $4 \mathrm{~d}$ in culture. This low percentage of $\mathrm{Tac}^{+}$cells in IL-2-containing cultures was not due to the masking of anti-Tac antibody binding sites by IL-2, because when cells were treated with glycin acidic buffer before staining, the same percentages of $\mathrm{Tac}^{+}$cells were detected. When anti-Tac antibody was added to cultures together with IL-2, B cell differentiation was only reduced by $\sim 30 \%$. This is consistent with the low number of $\mathrm{Tac}^{+}$cells in these cultures, and also, with the data of Ralph et al. (17), which demonstrate that the SKW cell line differentiated in response to high concentrations of IL-2 without expressing Tac antigens. This differentiation was not altered by the addition of anti-Tac antibody to cultures. In a series of experiments, we have separated $\mathrm{B}$ cells into $\mathrm{Tac}^{+}$and $\mathrm{Tac}^{-}$cells by positive selection of the former after 4-d culture in the presence of IL-2. Cells which bound anti-Tac antibody no longer differentiated in response to IL-2, possibly because of perturbations created by the binding of anti-Tac antibody to its receptor. Conversely, cells in the $\mathrm{Tac}^{-}$fraction did synthesize and secrete Ig. It is possible that there are $\mathrm{Tac}^{+}$cells in the negative fraction after elimination of $\mathrm{Tac}^{+}$cells due to the limitations of the positive selection techniques. On the other hand, it is possible that in vitro nonstimulated B cells differentiate in response to IL-2 without detectable levels of Tac antigen. It should be stressed that increasing concentrations of LPS from 0.01 to $1 \mu \mathrm{g} / \mathrm{ml}$ did not induce nor enhance human $B$ cell differentiation in the presence of IL-2. At the present time, it remains unclear why B cell differentiation in response to IL-2 occurred in the absence of detectable Tac antigen, which is currently considered to be the receptor for IL-2 on the cell membrane. Whether IL-2 could possibly bind to cells that have not been prestimulated in vitro with mitogen via a structure which is different from the Tac antigen displayed on the surface of in vitro mitogen-preactivated lymphocytes is currently under investigation.

When compared with cultures containing IL-2 alone, a marked increase in the amount of Ig secreted without noticeable change in the number of $\mathrm{Ig} \mathrm{CC}$ occurred in cultures in which high concentrations of recombinant IL-2 and recombinant $\gamma$ IFN were simultaneously added. Similarly, the number of PFC were found to be augmented when IL- 2 and $\gamma$-IFN were simultaneously present in cultures, whereas the number of Ig CC remained unchanged. Therefore, since $\gamma$-IFN alone was shown to be unable to trigger $B$ cell differentiation or to induce any increase in the number of Ig CC when used in combination with IL-2 (Table III), a likely hypothesis would be that $\gamma$-IFN selectively acted on the terminal differentiation of Ig-synthesizing cells into cells capable of secreting Ig. We are currently investigating whether, in addition to this effect, $\gamma$-IFN could also modulate quantitatively the Ig synthesis in cells initiated by IL-2.

In addition to demonstrating that the effects of $\gamma$-IFN are restricted to a precise phase of the $B$ cell maturation process (since $\gamma$-IFN did not induce Ig synthesis but only increased Ig secretion in IL-2 stimulated cultures), the present study provides experimental support for the concept that the in vitro differentiation of B cells into Ig-synthesizing cells and their further differentiation into Ig-secreting cells are distinct steps which can be individually regulated by different factors or signals. Such a concept has been repeatedly suggested $(1-3,14)$, although little experimental data clearly dissecting the consecutive sequences of the later phases of $B$ cell maturation have been reported. This observation, when coupled with the fact that no in vitro preincubation of the responding cells with polyclonal $B$ cell activators such as SAC or anti-IgM was required in order for them to respond to IL-2, may be helpful in attempts to correct immune disorders with lymphokines.

\section{Acknowledgments}

We thank Dr. H. Clifford Lane, Hoffman-LaRoche Corp., and Genentech Corp. for their support in providing lymphokines, and Dr. Thomas A. Waldmann and his co-workers for their gift of anti-Tac antibody. The technical assistance of Ms. Norma L. Witzel and the editorial assistance of Ms. Ann C. London and Ms. Dee Goodrich are gratefully acknowledged.

Lê thi Bich-Thuy is supported by U. S. Public Health Service International Research grant 1 F05 TW0338-01 BI.

\section{References}

1. Watson, J., and D. Mochizuki. 1980. Interleukin-2: a class of T cell growth factors. Immunol. Rev. 51:257-278.

2. Howard, M., and W. E. Paul. 1983. Regulation of B cell growth and differentiation by soluble factors. Annu. Rev. Immunol. 1:307-333. 
3. Moller, G., editor. 1982. Lymphokines and lymphocyte activation. Immunol. Rev. 63:5-209.

4. Sonnenfeld, G., A. D. Mandel, and T. C. Merigan. 1978. Time and dosage dependence of immunoenhancement by murine type II interferon preparations. Cell. Immunol. 40:285-293.

5. Zlotnik, A., K. Roberts, A. Vasil, E. Blumenthal, F. Larosa, H. J. Leibson, R. O. Endress, S. D. Graham, J. White, J. Hill, P. Henson, J. R. Klein, M. J. Bevan, P. Marrack, and J. W. Kappler. 1983. Coordinate production by a T cell hybridoma of $\gamma$-IFN and three other lymphokine activities: multiple activities of a single lymphokine. J. Immunol. 131: 794-800.

6. Leibson, J. H., M. Gefter, A. Zlotnik, P. Marrack, and J. W. Kappler. 1984. Role of $\gamma$-interferon in antibody-producing responses. Nature (Lond.). 309:799-801.

7. Sidman, C. L., J. D. Marshall, L. D. Shultz, P. W. Gray, and H. M. Johnson. 1984. $\gamma$-interferon is one of several direct B cell-maturing lymphokines. Nature (Lond.). 309:801-804.

8. Zubler, R. H., J. W. Lowenthal, F. Erard, N. Hashimoto, R. Devos, and H. R. MacDonald. 1984. Activated B cells express receptors for, and proliferate to, pure interleukin-2. J. Exp. Med. 160:1170-1183.

9. Tsudo, M., T. Uchiyama, and H. Uchino. 1984. Expression of Tac antigen on activated normal human B cells. J. Exp. Med. 160:612617.

10. Mingari, M. C., F. Gerrosa, G. Carra, R. S. Accola, A. Moretta, R. H. Zubler, T. A. Waldmann, and L. Moretta. 1984. Human interleukin-2 promotes proliferation of activated B cells via surface receptors similar to those of activated T cells. Nature (Lond.). 312:641-643.

11. Muraguchi, A., J. H. Kehrl, D. L. Longo, D. J. Volkman, K. A. Smith, and A. S. Fauci. 1985. Interleukin-2 receptors on human B cells. Implications for the role of interleukin-2 in human B cell functions. $J$. Exp. Med. 161:181-197.

12. Nakagawa, T., T. Hirano, N. Nakagawa, K. Yoshizaki, and T. Kishimoto. 1985. Effects of recombinant IL-2 and $\gamma$-IFN on proliferation and differentiation of human B cells. J. Immunol. 134:959-966.

13. Teranishi, T., T. Hirano, B. H. Lin, and K. Onoue. 1984. Dem- onstration of the involvement of interleukin-2 in the differentiation of Staphylococcus aureus Cowan-1-stimulated B cells. J. Immunol. 133 3062-3067.

14. Kishimoto, T., K. Yoshizaki, M. Kimoto, M. Okada, T. Kuritani, H. Kikutani, K. Shimizu, T. Nakagawa, N. Nakagawa, Y. Miki, H. Kishi, K. Fugumaga, T. Yoshikubo, and T. Taga. 1984. B cell growth and differentiation factors and mechanism of B cell activation. Immunol. Rev. 78:97-118.

15. Nakanishi, K., T. R. Malek, K. A. Smith, T. Hamaoka, E. M. Shevach, and W. E. Paul. 1984. Both interleukin-2 and a second T-cell derived factor in EL-4 supernatant have activity as differentiation factors in IgM synthesis. J. Exp. Med. 160:1605-1621.

16. Pure, E., P. C. Isakson, V. Paetkau, B. Caplan, E. S. Vitetta, and P. H. Kramer. 1982. Interleukin-2 does not induce murine B cells to secrete Ig. J. Immunol. 129:2420-2425.

17. Ralph, P., G. Jeong, K. Welte, R. Merstelman, H. Rabin, L. E. Henderson, L. M. Souza, T. C. Boone, and R. J. Robb. 1984. Stimulation of immunoglobulin secretion in human B lymphocytes as a direct effect of high concentrations of IL-2. J. Immunol. 133:2442-2445.

18. Lê thi Bich-Thuy, C. Samarut, J. Brochier, W. H. Fridman, and J. P. Revillard. 1980. Suppression of mitogen-induced peripheral B cell differentiation by soluble FCR released by lymphocytes. Eur. J. Immunol. 10:894-898.

19. Volkman, D. J., H. C. Lane, and A. S. Fauci. 1981. Antigeninduced in vitro antibody production in humans: a model for B cell activation and immunoregulation. Proc. Natl. Acad. Sci. USA. 78:25282531 .

20. Ortaldo, J. R., and R. B. Herberman. 1984. Heterogeneity of natural killer cells. Annu. Immunol. Rev. 2:359-394.

21. Smith, K. A. 1984. Interleukin-2. Annu. Rev. Immunol. 2:219333.

22. Robb, R. J., W. C. Warner, and C. M. Rusk. 1984. Low and high cellular receptors for interleukin 2. Implications for the level of Tac antigens. J. Exp. Med. 160:1126-1146. 